\section{Using Quality Improvement Methodology to Standardize Procedures of the 6 Minute Walk Test on an Inpatient Cardiopulmonary Program}

\section{Danielle Griscti Vaidyan and Danielle Struble-Fitzsimmons*}

Rehabilitation Services Division, Burke Rehabilitation Hospital, White Plains, NY, USA

\begin{abstract}
Background: The 6-Minute Walk Test (6MWT) assesses aerobic capacity and endurance and is recommended for use in the geriatric cardiopulmonary patient population. 6MWT procedures should follow the gold standard guidelines described by American Thoracic Society (ATS) to ensure reliability and validity of measurement. The Plan-DoStudy-Act (PDSA) quality improvement framework can be utilized by physical therapists to systematically improve clinical practice when deviations from the standard of care are identified. The purpose of this study was to utilize a PDSA cycle to implement standardization of the 6MWT in an inpatient cardiopulmonary rehabilitation setting.

Methods: The full quality improvement cycle took a total of 8 months to complete. The project required the development of new training materials, changes to testing locations and processes, and modifications to the Electronic Medical Record (EMR). Outcome measures were identified in two domains: (1) staff training and (2) patient related.

Results: 35 physical therapy staff were trained. A between groups design was used to compare the old and new 6MWT measurements. Pulmonary patients who completed the 6MWT with the new format walked significantly farther than patients who completed the 6MWT using the old format, $t(84)=-2.29, p=0.025$. Cardiac patients who completed the 6MWT with the new format had no significant difference compared to old format, $t(75)=-.02, p=0.986$.
\end{abstract}

${ }^{*}$ Corresponding author: Danielle Struble-Fitzsimmons, Rehabilitation Services Division, Burke Rehabilitation Hospital, White Plains, NY, USA, Tel: +1 $914597-$ 2843; E-mail: dstruble@burke.org

Citation: Vaidyan DG, Struble-Fitzsimmons D (2020) Using Quality Improvement Methodology to Standardize Procedures of the 6 Minute Walk Test on an Inpatient Cardiopulmonary Program. J Gerontol Geriatr Med 6: 081.

Received: December 18, 2020; Accepted: December 28, 2020; Published: December 31, 2020

Copyright: () 2020 Vaidyan DG, et al. This is an open-access article distributed under the terms of the Creative Commons Attribution License, which permits unrestricted use, distribution, and reproduction in any medium, provided the original author and source are credited.

\begin{abstract}
Conclusion: The data from this project showed that pulmonary patients walked 111.32 feet farther on the 6MWT when tested with the new format when compared to the old format, representing a significant difference. This finding indicates that proper administration of the 6MWT using ATS standards is critical to obtaining valid and accurate measurements. The PDSA methodology allowed for improved physical therapist clinical practice within a cardiopulmonary rehabilitation program.
\end{abstract}

Keywords: Cardiopulmonary rehabilitation; 6 Minute walk test; Physical therapy; Plan-do-study-act; Quality improvement

\section{Abbreviations}

6MWT: 6-minute walk test

ATS: American Thoracic Society

PDSA: Plan-Do-Study-Act

IRF: Inpatient Rehabilitation Facility

EMR: Electronic Medical Record

RPE: Rate of Perceived Exertion

RPD: Rate of Perceived Dyspnea

\section{Introduction}

The 6-Minute Walk Test (6MWT) is a submaximal exercise test that is used to assess aerobic capacity and endurance [1]. It has been found to be a reliable tool for evaluation of older populations ( $\geq 65$ years) with chronic heart failure, and can be used as a predictor of pulmonary related hospitalizations and all-cause mortality [2-4]. In an inpatient rehabilitation setting, the $6 \mathrm{MWT}$ is used by physical therapists to measure a patient's baseline status, identify progress, justify services, and allow clinicians to set attainable and meaningful goals. Patients also benefit from use of the measurement tool for self-monitoring functional progress $[5,6]$. To be a valid and reliable assessment, however, the 6MWT procedures must be followed according to American Thoracic Society (ATS) guidelines. Published in 2002, these testing procedures are considered the gold standard, and have very specific guidelines regarding test administration [5].

Quality improvement methodology is an important tool in healthcare delivery, and is modeled to improve clinical practice. A commonly used framework for Quality Improvement (QI) is the PlanDo-Study-Act (PDSA) cycle. This successful problem-solving model was initially developed for product manufacturing by Deming (1986), and was adapted by Langley (1996) for use in healthcare. PDSA is a four-stage problem solving model used for improving a practice and carrying out change. The "plan" phase defines the objective, identifies and analyzes the problem, and puts a plan into action. The "do" phase consists of plan execution and data collection. In the "study" phase data analysis and summary are completed. The "act" phase ends the cycle by taking an account of recommended outcomes and adoption or modification of practice [7]. 
The authors determined that there was a need to standardize $6 \mathrm{MWT}$ procedures used by physical therapists in an inpatient cardiopulmonary program since the clinical test procedures used were not consistent with the gold standard practice described by the ATS [5]. Inconsistencies included test instructions, patient preparation, testing location, therapist encouragement and distance measurement techniques. To adopt the standardized 6MWT procedures in a systematic manner, a PDSA cycle was completed. The purpose of this study was to utilize quality improvement methodology to implement standardization of the 6MWT procedures in an inpatient cardiopulmonary rehabilitation setting.

\section{Materials}

This quality improvement project was completed in a specialized cardiopulmonary rehabilitation program located within a suburban New York Inpatient Rehabilitation Facility (IRF). The program serves a primarily geriatric population, with a mean patient age of 72.4 years. Patients receive comprehensive physical rehabilitation services for diagnoses such as chronic obstructive pulmonary disease, interstitial lung disease, and myocardial infarction, as well as postoperative patients after coronary artery bypass graft, valve repair and heart or lung transplant. The 6MWT was a core assessment utilized by the program, and was measured by physical therapists for all patients on initial evaluation, weekly assessments, and discharge evaluations. The PDSA cycle framework was used to standardize the 6MWT to ATS standards $[5,4]$. The entire project was developed and managed by the authors, whose roles are staff physical therapist and program director, respectively. The full quality improvement cycle took a total of 8 months to complete, beginning with the planning phase in March 2019, and ending with the act phase in October 2019. The planning phase lasted 2 months and revolved around three main questions: why are we changing, what are we changing, and what data needs to be collected?

During the planning phase, multiple deviations from the standardized 6 MWT procedures were identified in the domains of patient instruction, preparation, encouragement and test location. Under the old test procedures, clinicians were instructing patients to ambulate as far as they were able to for the test, however patients would be encouraged to sit prematurely if desired. Patient preparation varied regarding exercise intensity prior to 6 MWT assessment, and use of an assistive device also varied during testing. The old testing location made a loop pattern in a crowded gym and hallway environment instead of the quiet, long hallway recommended by ATS. Verbal encouragement varied from one clinician to another, and was provided inconsistently instead of the recommended one minute intervals. Upon completion of the test, therapists calculated distances walked adding together those distances measured after seated rest breaks, rather than stopping the test when a patient sat down. Changes made were aligned specifically with ATS guidelines for administration of 6MWT. Over a month, meetings took place with the research team to measure and mark two chosen corridors at appropriate lengths. Both test locations, a primary location, and secondary back-up option, were uncrowded straight hallways $30 \mathrm{~m}$ in length. Two pieces of tape on the walls were used to mark the new courses, to ensure therapists performing the test completed testing at the same locations during each trial. Testing documents were developed in both paper and electronic form. The paper document was presented to staff as a worksheet of required information for
Electronic Medical Record (EMR). The worksheet was provided on a clipboard during performance of the test and clarified test location and post-test vital signs. In addition, a pocket-sized clinical guide was developed to ensure consistent dictation of instructions and phrases of encouragement. EMR modifications were made to reflect new procedures to ensure that all necessary data were captured, and included: test location, distance walked, device used, assistance level, supplemental oxygen use and oxygen caddy management. Post-test vital signs (Borg Rate of Perceived Exertion (RPE) and Dyspnea (RPD), heart rate, blood pressure, respiratory and oxygen saturation) were also included in this documentation. The only new equipment ordered for the change were 3 small lap counters; these were purchased and hung in a central location within the therapy gym to ensure easy access for testing. Training documents were developed for review of practice guidelines including a Word document and PowerPoint presentation. The PowerPoint presentation included a training video that reviewed required equipment, test location, instruction for test, and various scenarios for management of patients. Information reviewed was provided to clinicians on a centralized database to ensure overall adherence to new protocols.

\section{Methods}

Changes were actively implemented during a 3-month time period. Staff training occurred in two phases. During phase one, the core cardiopulmonary therapy team was provided with a didactic presentation of the new standard of practice, and in-person follow up training sessions were provided to ensure staff consistently demonstrated competency adhering to the protocol. In phase two, a second training presentation was provided to the hospital's physical therapy staff from the other four inpatient programs to account for cross-covering patients on the cardiopulmonary program.

The new test procedures, aligned to ATS standards, were implemented concurrently with staff training, and lasted for a period of three months. During this process, all testing changes identified in the planning phase were implemented. Under the new procedure, all 6MWT tests were completed at the start of a therapy session before any rigorous physical activity occurred. Patients were transported via wheelchair to either of the two hallway testing locations and were provided with scripted instructions at the start of the test. Therapists used standardized phrases of encouragement at minute intervals during test administration. Patients were able to use their usual walking aids during the test (cane, walker, etc.,). Upon test completion patient post-test vitals and RPE/RPD were recorded. All clinical findings were entered into the new 6MWT template in the electronic medical record.

Outcome measures were identified in 2 domains: (1) staff training and (2) patient related. Staff related data would include the number of physical therapy staff trained in the new process. Patient related data included 6MWT distances pre and post the procedural change.

\section{Results}

This study met local criteria as a quality improvement project and did not need Institutional Review Board (IRB) review. Data analysis took a period of 3 months. Staff related data were obtained from retrospective review of in-service attendance logs. Patient related data were obtained from retrospective reviews of the electronic medical records. A between groups design was used to allow for comparison. 
Citation: Vaidyan DG, Struble-Fitzsimmons D (2020) Using Quality Improvement Methodology to Standardize Procedures of the 6 Minute Walk Test on an Inpatient Cardiopulmonary Program. J Gerontol Geriatr Med 6: 081.

The old format group was those patients who had a physical therapy evaluation completed during the 3-month period prior to change. The new format group included those patients tested using the new format during a 3-month period. Patients were excluded from analysis if data were missing or if they did not have a cardiac or pulmonary diagnosis. The medical records were reviewed for five specific variables: (1) diagnosis, (2) gender, (3) age, (4) date of initial physical therapy evaluation and (5) 6MWT distance on evaluation. All data were analyzed with Statistical Package for Social Sciences (SPSS) version 24 [8].

\section{Staff outcomes}

Two in-service presentations were given to physical therapists in the facility. The first in-service was presented to 8 physical therapists on the cardiopulmonary program. These same physical therapists also completed in-person follow up training with the QI project lead (DGV). The second training in-service was presented to 27 physical therapists who were assigned to other inpatient programs, but at times were required to complete coverage on the cardiopulmonary program.

\section{Patient outcomes}

Pulmonary patients: The total pulmonary group sample size was $\mathrm{N}$ $=86.41$ patients were tested using the old 6MWT format and 45 patients were tested using the new format. The average age of the old format group was 69.80 years $(\mathrm{SD}=9.84)$, with a minimum age of 48 and a maximum age of 89 . The average age of the new format group was $72.93(\mathrm{SD}=12.16)$, with a minimum age of 43 years old and a maximum age of 98 years old. The mean age of the old format group $(\mathrm{M}=69.80, \mathrm{SD}=9.84)$ was not significantly different from that of the new format group $(\mathrm{M}=72.93$ years; $\mathrm{SD}=12.16), \mathrm{t}(84)=-1.30, \mathrm{p}$ $=0.196$. Both groups had similar gender proportions. The old format group was $61 \%$ female $(\mathrm{n}=25)$ and $39 \%$ male $(\mathrm{n}=16)$. The new format group was $62.2 \%$ female $(n=28)$ and $37.8 \%$ male $(n=17)$. The mean 6MWT distance for the old format group was 263.88 feet $(\mathrm{SD}=215.88)$ and the mean distance for the new format group was 375.20 ( $\mathrm{SD}=234.22$ ). Patients who completed the 6MWT with the new format walked significantly farther than patients who completed the 6MWT using the old format, $\mathrm{t}(84)=-2.29, \mathrm{p}=0.025$.

Cardiac patients: The total cardiac group sample size was $\mathrm{N}=77$. 48 patients were tested using the old 6MWT format and 29 patients were tested using the new format. The average age of the old format group was 72.06 years $(\mathrm{SD}=14.60)$, with a minimum age of 24 and a maximum age of 98 . The average age of the new format group was $74.10(\mathrm{SD}=11.04)$, with a minimum age of 47 years old and a maximum age of 91 years old. The mean age of the old format group $(\mathrm{M}=72.06, \mathrm{SD}=14.60)$ was not significantly different from that of the new format group $(\mathrm{M}=74.10$ years; $\mathrm{SD}=11.04), \mathrm{t}(75)=-.65$, $\mathrm{p}=0.519$. The groups varied in gender proportions. The old format group was $39.6 \%$ female $(\mathrm{n}=19)$ and $60.4 \%$ male $(\mathrm{n}=29)$. The new format group was $58.6 \%$ female $(\mathrm{n}=17)$ and $41.4 \%$ male $(\mathrm{n}=12)$. The mean 6MWT distance for the old format group was 373.21 feet $(\mathrm{SD}=218.96)$ and the mean distance for the new format group was 374.28 ( $\mathrm{SD}=316.35)$. There was no significant difference between 6MWT distances between the two groups, $\mathrm{t}(75)=-.02, \mathrm{p}=0.986$.

\section{Discussion}

The data from this project showed that pulmonary patients walked 111.32 feet farther on the 6MWT when tested with the new format when compared to the old format, representing a significant difference. We hypothesize that using the old procedures, therapists were encouraging patients to sit prematurely, particularly those patients who demonstrated dyspnea during testing, thus leading to shorter 6MWT distances. Using the new protocol, however, therapists used a scripted statement for rests which allowed patients to take standing rest breaks without ending the test, allowing for longer $6 \mathrm{MWT}$ distances. Interestingly, there was only a 1.07 -foot increase in 6MWT distances for cardiac patients tested with the new format; this difference was not significant when compared to the old format. It is possible that 6MWT distances for cardiac patients were less influenced by the old, incorrect test procedures, accounting for less of a difference. A second explanation of this finding may be that the current samples, which were not proportionate in size or gender, were not representative and were unable to capture a difference.

Within the physical therapy profession there is limited qualitybased literature. Quality improvement methodology can strengthen clinical practice by improving decision making so that patients are impacted positively [9]. A question that arises regarding quality-based research is a clinician's ability to perform a quality improvement project in a work environment focused on patient care. There are limitations for a clinician's ability to perform both research and data analysis within a patient centered environment. Another barrier to completion includes a clinician's statistical knowledge to analyze data. The research that was performed during this quality improvement project was completed by a physical therapist that has advanced statistical training, as well as an administrative role within the rehabilitation facility. Having an administrative role allowed for flexibility to collect and analyze data within a clinical environment. Educational meetings and materials were developed by a staff physical therapist, however without the ability to analyze data there is no way to quantify change.

In summary, the use of the PDSA cycle for quality improvement in this inpatient rehabilitation setting allowed for improved clinical practice within this cardiopulmonary program, and all modifications described have been adopted. This project allowed clinicians to obtain valid and reliable distance measurements for justification of services and identification of patient improvement. Implementation of this standardization resulted in a successful change in clinical practice, and physical therapists are encouraged to participate in quality improvement initiatives to enhance care delivery, despite the challenges to this in clinical settings.

\section{Acknowledgement}

Both authors affirm this work as original, and both authors met criteria for authorship. No funds were used in this project. Neither author has any conflicts of interest to disclose.

\section{References}

1. Spruit MA, Polkey MI, Celli B, Edwards LD, Watkins ML, et al. (2012) Predicting outcomes from 6-minute walk distance in chronic obstructive pulmonary disease. J Am Med Dir Assoc 13: 291-297.

2. Durheim MT, Smith PJ, Babyak MA, Mabe SK, Martinu T, et al. (2015) Six-minute-walk distance and accelerometry predict outcomes in chronic obstructive pulmonary disease independent of Global Initiative for Chronic Obstructive Lung Disease 2011 Group. Ann Am Thorac Soc 12: 349356. 
Citation: Vaidyan DG, Struble-Fitzsimmons D (2020) Using Quality Improvement Methodology to Standardize Procedures of the 6 Minute Walk Test on an Inpatient Cardiopulmonary Program. J Gerontol Geriatr Med 6: 081.

3. Uszko-Lencer NHMK, Mesquita R, Janssen E, Werter C, Brunner-La Rocca HP, et al. (2017) Reliability, construct validity and determinants of 6-minute walk test performance in patients with chronic heart failure. Int J Cardiol 240: 285-290.

4. Casillas JM, Hannequin A, Besson D, Benaïm S, Krawcow C, et al. (2013) Walking tests during the exercise training: Specific use for the cardiac rehabilitation. Ann Phys Rehabil Med 56: 561-575.

5. ATS Committee on Proficiency Standards for Clinical Pulmonary Function Laboratories (2002) ATS statement: guidelines for the six-minute walk test. ATS Committee on Proficiency Standards for Clinical Pulmonary Function Laboratories. Am J Respir Crit Care Med166: 111-117.

6. Stevens JG, Beurskens AJ (2010) Implementation of measurement instruments in physical therapist practice: Development of a tailored strategy. Phys Ther 90: 953-961.
7. Taylor MJ, McNicholas C, Nicolay C, Darzi A, Bell D, et al. (2014) Systematic review of the application of the plan-do-study-act method to improve quality in healthcare. BMJ Qual Safe 23: 290-298.

8. IBM Corp (2016) IBM SPSS Statistics for Windows, Version 24.0. IBM Corp, Armonk, NY, USA.

9. Westby MD, Klemm A, Li LC, Jones CA (2016) Emerging Role of Quality Indicators in Physical Therapist Practice and Health Service Delivery. Phys Ther 96: 90-100. 


\section{Hif}

Advances In Industrial Biotechnology | ISSN: 2639-5665

Advances In Microbiology Research | ISSN: 2689-694X

Archives Of Surgery And Surgical Education | ISSN: 2689-3126

Archives Of Urology

Archives Of Zoological Studies | ISSN: 2640-7779

Current Trends Medical And Biological Engineering

International Journal Of Case Reports And Therapeutic Studies | ISSN: 2689-310X

Journal Of Addiction \& Addictive Disorders | ISSN: 2578-7276

Journal Of Agronomy \& Agricultural Science | ISSN: 2689-8292

Journal Of AIDS Clinical Research \& STDs | ISSN: 2572-7370

Journal Of Alcoholism Drug Abuse \& Substance Dependence | ISSN: 2572-9594

Journal Of Allergy Disorders \& Therapy | ISSN: 2470-749X

Journal Of Alternative Complementary \& Integrative Medicine | ISSN: 2470-7562

Journal Of Alzheimers \& Neurodegenerative Diseases | ISSN: 2572-9608

Journal Of Anesthesia \& Clinical Care | ISSN: 2378-8879

Journal Of Angiology \& Vascular Surgery | ISSN: 2572-7397

Journal Of Animal Research \& Veterinary Science | ISSN: 2639-375

Journal Of Aquaculture \& Fisheries | ISSN: 2576-5523

Journal Of Atmospheric \& Earth Sciences | ISSN: 2689-8780

Journal Of Biotech Research \& Biochemistry

Journal Of Brain \& Neuroscience Research

Journal Of Cancer Biology \& Treatment | ISSN: 2470-7546

Journal Of Cardiology Study \& Research | ISSN: 2640-768X

Journal Of Cell Biology \& Cell Metabolism | ISSN: 2381-1943

Journal Of Clinical Dermatology \& Therapy | ISSN: 2378-8771

Journal Of Clinical Immunology \& Immunotherapy | ISSN: 2378-8844

Journal Of Clinical Studies \& Medical Case Reports | ISSN: 2378-880

Journal Of Community Medicine \& Public Health Care | ISSN: 2381-1978

Journal Of Cytology \& Tissue Biology | ISSN: 2378-9107

Journal Of Dairy Research \& Technology | ISSN: 2688-9315

Journal Of Dentistry Oral Health \& Cosmesis | ISSN: 2473-6783

Journal Of Diabetes \& Metabolic Disorders | ISSN: 2381-201X

Journal Of Emergency Medicine Trauma \& Surgical Care | ISSN: 2378-8798

Journal Of Environmental Science Current Research | ISSN: 2643-5020

Journal Of Food Science \& Nutrition | ISSN: 2470-1076

Journal Of Forensic Legal \& Investigative Sciences | ISSN: 2473-733X

Journal Of Gastroenterology \& Hepatology Research | ISSN: 2574-2566
Journal Of Genetics \& Genomic Sciences | ISSN: 2574-2485

Journal Of Gerontology \& Geriatric Medicine | ISSN: 2381-8662

Journal Of Hematology Blood Transfusion \& Disorders | ISSN: 2572-2999

Journal Of Hospice \& Palliative Medical Care

Journal Of Human Endocrinology | ISSN: 2572-9640

Journal Of Infectious \& Non Infectious Diseases | ISSN: 2381-8654

Journal Of Internal Medicine \& Primary Healthcare | ISSN: 2574-2493

Journal Of Light \& Laser Current Trends

Journal Of Medicine Study \& Research | ISSN: 2639-5657

Journal Of Modern Chemical Sciences

Journal Of Nanotechnology Nanomedicine \& Nanobiotechnology | ISSN: 2381-2044

Journal Of Neonatology \& Clinical Pediatrics | ISSN: 2378-878X

Journal Of Nephrology \& Renal Therapy | ISSN: 2473-7313

Journal Of Non Invasive Vascular Investigation | ISSN: 2572-7400

Journal Of Nuclear Medicine Radiology \& Radiation Therapy | ISSN: 2572-7419

Journal Of Obesity \& Weight Loss | ISSN: 2473-7372

Journal Of Ophthalmology \& Clinical Research | ISSN: 2378-8887

Journal Of Orthopedic Research \& Physiotherapy | ISSN: 2381-2052

Journal Of Otolaryngology Head \& Neck Surgery | ISSN: 2573-010X

Journal Of Pathology Clinical \& Medical Research

Journal Of Pharmacology Pharmaceutics \& Pharmacovigilance | ISSN: 2639-5649

Journal Of Physical Medicine Rehabilitation \& Disabilities | ISSN: 2381-8670

Journal Of Plant Science Current Research | ISSN: 2639-3743

Journal Of Practical \& Professional Nursing | ISSN: 2639-568

Journal Of Protein Research \& Bioinformatics

Journal Of Psychiatry Depression \& Anxiety | ISSN: 2573-0150

Journal Of Pulmonary Medicine \& Respiratory Research | ISSN: 2573-0177

Journal Of Reproductive Medicine Gynaecology \& Obstetrics | ISSN: 2574-2574

Journal Of Stem Cells Research Development \& Therapy | ISSN: 2381-2060

Journal Of Surgery Current Trends \& Innovations | ISSN: 2578-7284

Journal Of Toxicology Current Research | ISSN: 2639-3735

Journal Of Translational Science And Research

Journal Of Vaccines Research \& Vaccination | ISSN: 2573-0193

Journal Of Virology \& Antivirals

Sports Medicine And Injury Care Journal | ISSN: 2689-8829

Trends In Anatomy \& Physiology | ISSN: 2640-7752

Submit Your Manuscript: https://www.heraldopenaccess.us/submit-manuscript 